\title{
THE CONNECTION BETWEEN SERUM PROLACTIN, TSH AND INSULIN RESISTANCE IN POLYCYSTIC OVARY SYNDROME PATIENTS
}

\author{
Alice Albu 1,2, Serban Radian², Suzana Florea ${ }^{3}$, Simona Fica ${ }^{1,2}$ \\ 1 Elias Hospital, Department of Endocrinology; 2 „Carol Davila” University of Medicine and Pharmacy; 3 \\ Elias Hospital, Laboratory
}

Introduction: both TSH and prolactin serum levels within normal range were previously reported to be associated with metabolic parameters.

Aim: to analyze the connections between serum levels of prolactin, TSH and insulin resistance in polycystic ovary syndrome patients.

Material and methods: 322 PCOS patients (mean age $24.3 \pm 5.16$ yrs, mean body mass index $28 \pm 7.57$ $\mathrm{kg} / \mathrm{m} 2$ ) with normal serum prolactin and without thyroid dysfunction evaluated between January 2007 and January 2014 were included in the study. Anthropometric, metabolic and hormonal parameters were measured in all the patients. HOMA-IR was calculated as an index of insulin resistance.

Results: HOMA-IR was negatively correlated with serum prolactin $(r=-0,149, p=0.001)$ and positively with serum TSH $(r=0,207, p=0.03)$ and with adiposity indices (BMI $p<0.0001$, waist $p<0.0001$, waist-hip ratio $p<0.0001$ ). In multivariate linear regression both prolactin (beta $=-0.203, p=0.015$ ) and TSH (beta $=$ $0.165, p<0.05$ ) were independently associated with HOMA-IR. Several models of multivariate linear regression were built with HOMA-IR as dependent variable and all the parameters associated with HOMAIR in bivariate analysis as independent variables. In each model one of the adiposity indices (BMI, waist or waist-hip ratios) were included in order to avoid collinearity. In these models the only independent predictor for HOMA-IR was adiposity.
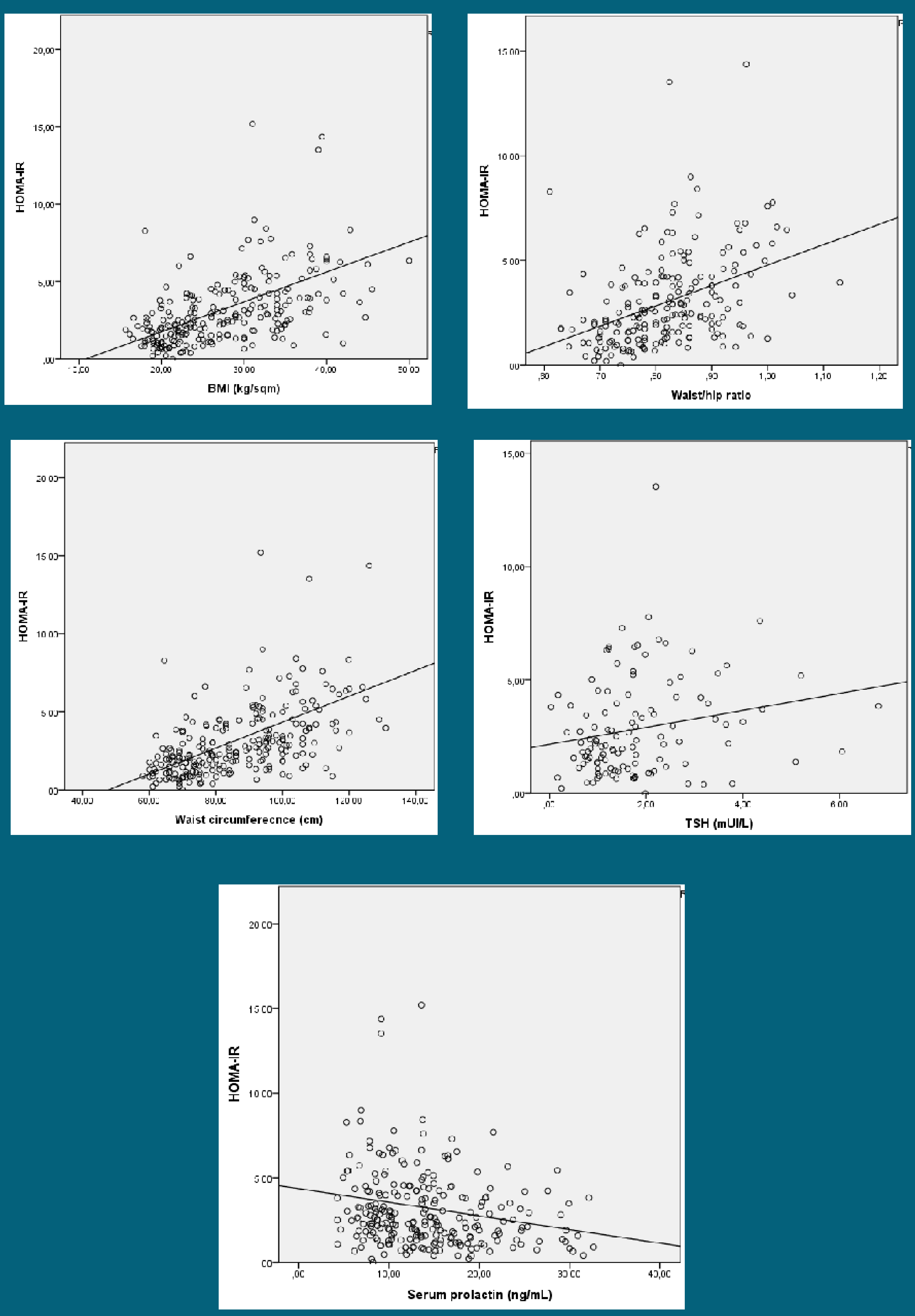

Conclusion: although both TSH and prolactin serum levels were related to insulin resistance, this connection seems to be due to the interplay between adiposity and all these parameters in PCOS patients.

\begin{tabular}{|c|c|c|c|c|}
\hline Model 1 & B & Std. Error & Beta & $P$ value \\
\hline Prolactin & $-0,036$ & 0,035 & $-0,094$ & 0,314 \\
\hline Age & $-0,039$ & 0,036 & $-0,099$ & 0,279 \\
\hline Waist/hip ratio & 10,553 & 2,099 & 0,474 & 0,000 \\
\hline TSH & 0,273 & 0,178 & 0,136 & 0,127 \\
\hline Model 2 & B & Std. Error & Beta & $P$ value \\
\hline Prolactin & $-0,036$ & 0,027 & $-0,100$ & 0,183 \\
\hline Age & $-0,049$ & 0,030 & $-0,124$ & 0,103 \\
\hline TSH & 0,224 & 0,133 & 0,124 & 0,093 \\
\hline $\mathrm{BMI}$ & 0,174 & 0,021 & 0,615 & 0,000 \\
\hline Model 3 & B & Std. Error & Beta & $P$ value \\
\hline Prolactin & $-0,016$ & 0,028 & $-0,044$ & 0,569 \\
\hline Age & $-0,057$ & 0,030 & $-0,145$ & 0,062 \\
\hline TSH & 0,202 & 0,135 & 0,112 & 0,136 \\
\hline Waist circumf & 0,075 & 0,009 & 0,625 & 0,000 \\
\hline
\end{tabular}

Models of multivariate linear regression with HOMA-IR as dependent variable 